\title{
A specific scoring system able to predict the efficacy of the therapy for bladder cancer: why not?
}

\author{
Fabrizio Dal Moro ${ }^{1,2}$ (1)
}

Received: 7 October 2018 / Accepted: 15 October 2018 / Published online: 23 October 2018

c) Springer-Verlag GmbH Germany, part of Springer Nature 2018

\section{Dear Editor,}

I would like to congratulate Soria et al. [1] on their recent review focused on the role of urine-, tissue- and blood-based markers in diagnosing bladder cancer (BC). The authors analyzed the standard and novel markers demonstrating that there is little and often poor evidence to justify the use of a single specific marker in clinical practice.

As underlined by the above authors and reported in some other studies, the use of a comprehensive pathway of different tests may be more useful in clinical care rather than a single marker: a combination of the analysis of different markers could improve the general sensitivity and specificity of $\mathrm{BC}$ diagnosis, through the evaluation of the different functional targets of each analyzed parameter [2].

This strategy may be extremely useful not only in finding $\mathrm{BC}$ at early stage, but also (and above all) in monitoring the response to local/systemic therapies.

The definition of a specific pathway of biochemical markers which are highly efficacious in the early identification of patients as 'non-responders' to the treatment may be crucial to make them candidate to a more radical therapy earlier, such as radical cystectomy, thereby reducing the risk of a localized progression and/or a distant metastasizing.

Moreover, the accuracy of a similar multiple test could be increased by adding other parameters well known to be predictors of response/non-response to the therapy: for example, in our experience in patients affected by non-muscle invasive $\mathrm{BC}$, treated with bladder instillation of $\mathrm{BCG}$, we demonstrated, in a large cohort, that there are some factors

Fabrizio Dal Moro

fabrizio.dalmoro@unipd.it

1 Department of Surgery, Oncology and Gastroenterology, Urology, University of Padova, Via Giustiniani 2, 35128 Padua, Italy

2 Urologic Clinic, "Santa Maria della Misericordia" Hospital, University of Udine, Udine, Italy which do not influence the efficacy of the treatment such as age [3], while others, such as hypertension [4], are significantly correlated to a poor response to immunotherapy.

Multicenter studies focused on this topic could define the specific single "weight" of each parameter more successfully, thus allowing the creation of a specific scoring system able to predict the efficacy of the therapy better and consequently 'tailoring' the best radical intervention on the best patient.

Author contributions Protocol/project development: Fabrizio Dal Moro; manuscript writing/editing: Fabrizio Dal Moro.

\section{Compliance with ethical standards}

Conflict of interest The author declares that he has no conflict of interest.

\section{References}

1. Soria F, Krabbe LM, Todenhöfer T, Dobruch J, Mitra AP, Inman BA, Gust KM, Lotan Y, Shariat SF (2018) Molecular markers in bladder cancer. World J Urol. https://doi.org/10.1007/s0034 5-018-2503-4

2. Dal Moro F, Valotto C, Guttilla A, Zattoni F (2013) Urinary markers in the everyday diagnosis of bladder cancer. Urologia 80:265-275. https://doi.org/10.5301/urologia.5000041

3. Dal Moro F, Rossi A, Zattoni F (2013) Does age really matter in the choice of treatment for bladder cancer? Br J Cancer 108:24152416. https://doi.org/10.1038/bjc.2013.239

4. Dal Moro F, Bovo A, Crestani A, Vettor R, Gardiman MP, Zattoni F (2015) Effect of hypertension on outcomes of high-risk patients after BCG-treated bladder cancer: a single-institution long follow-up cohort study. Medicine (Baltimore) 94:e589. https://doi. org/10.1097/MD.0000000000000589 